\title{
Doppler echocardiographic measurement of cardiac output using the mitral orifice method
}

\author{
YUN ZHANG, SIGURD NITTER-HAUGE, HALFDAN IHLEN, ERIK MYHRE \\ From the Medical Department B, Rikshospitalet, University Hospital, Oslo, Norway
}

SUMmARY Cardiac output was determined in 20 patients with various cardiac conditions by measuring the cross sectional area of the mitral orifice by echocardiography and the transmitral flow by the Doppler technique. Cardiac output was calculated by multiplying the corrected mitral orifice area by the maximum diastolic velocity integral recorded by the pulsed mode. The results were compared with that obtained by the Fick method. The correlation for cardiac output by the two techniques was high in the whole group, particularly in patients without mitral regurgitation. There was also a good correlation for stroke volume determined by the two methods. Cardiac output was significantly overestimated by the continuous mode and in patients with mitral regurgitation. These results show that the mitral orifice method provides a new and reliable approach to the non-invasive measurement of cardiac output.

With the advent of Doppler echocardiography there has been an increased interest in estimating cardiac output by measuring aortic flow. ${ }^{2}$ Although satisfactory results have been reported using different models, the true value of determining the aortic cross sectional area method remains in dispute. This technique is invalid in patients with an abnormal aortic valve. ${ }^{3-6}$ An alternative approach to estimating cardiac output is to measure blood flow through the mitral orifice. Preliminary results obtained in animal experiments have been promising. ${ }^{7}$ There have, however, been few clinical studies using this approach. We therefore undertook the present study to evaluate the feasibility and validity of this method in clinical practice.

\section{Patients and methods}

\section{STUDY POPULATION}

Twenty consecutive patients (11 men and nine women, ranging in age from 17 to 65 years) were studied. All patients gave their informed consent to participate in the study and underwent right heart catheterisation with measurement of cardiac output

Requests for reprints to Dr Yun Zhang, Medical Department B, Rikshospitalet, University Hospital, Oslo 1, Norway.

Accepted for publication 9 October 1984 by the Fick method. The Table shows the clinical diagnoses. All patients were in sinus rhythm. Doppler echocardiography and right heart catheterisation were performed within 24 hours by different investigators, and the results were not compared until after the study was completed.

\section{THEORETICAL CONSIDERATIONS}

Transmitral flow (MF) can be calculated as: $M F=\int \bar{V}(t) \operatorname{CSA}(t) d t$ where $\bar{V}$ is the spatial mean blood velocity, CSA is the cross sectional area of the mitral orifice, and $t$ indicates that both $\bar{V}$ and CSA are functions of time.

The maximal mitral orifice area can readily be measured from the parasternal left ventricular short axis view. Since the mitral orifice area, however, changes considerably during diastole the maximal area must be corrected for such variations. Assuming that the normal mitral valve orifice varies throughout diastole as a series of ellipses, the changes of the mediolateral diameters of these ellipses are so small relative to those of anteroposterior diameters that these changes can be ignored. In such circumstances, the changes in area will be directly proportional to changes in anteroposterior diameter, which are shown on the derived $M$ mode echocardiograms. By this technique, we can obtain a ratio of the mean to maximal opening of the mitral orifice. This ratio multiplied by the maximal mitral orifice area equals the mean or 
Table Results of Doppler echocardiography in 20 patients

\begin{tabular}{|c|c|c|c|c|c|c|c|c|}
\hline Case No & Diagnosis & $M M A\left(\mathrm{~cm}^{2}\right)$ & $M O R$ & $C M A\left(\mathrm{~cm}^{2}\right)$ & $D V I(\mathrm{~cm})$ & $\begin{array}{l}H R(D) \\
\text { (beats/min) }\end{array}$ & $S V(D)\left(\mathrm{cm}^{3}\right)$ & $C O(D)(l / \min )$ \\
\hline $\begin{array}{r}1 \\
2 \\
3 \\
4 \\
5 \\
6 \\
7 \\
8 \\
9 \\
10 \\
11 \\
12 \\
13 \\
14 \\
15 \\
16\end{array}$ & $\begin{array}{l}\text { CAD } \\
\text { Normal } \\
\text { CAD } \\
\text { PS } \\
\text { CAD } \\
\text { HCM } \\
\text { CAD } \\
\text { Normal } \\
\text { CAD and VA } \\
\text { MR } \\
\text { AV } \\
\text { PE } \\
\text { Normal } \\
\text { HCM } \\
\text { CAD and VA } \\
\text { CAD, VA, }\end{array}$ & $\begin{aligned} 9.58 \\
6.98 \\
4.65 \\
8.38 \\
8.95 \\
6.50 \\
9.16 \\
7.42 \\
9.82 \\
9.72 \\
7.11 \\
10.60 \\
9.44 \\
7.48 \\
8.26 \\
11.02\end{aligned}$ & $\begin{array}{l}0.55 \\
0.61 \\
0.72 \\
0.57 \\
0.52 \\
0.80 \\
0.52 \\
0.62 \\
0.57 \\
0.63 \\
0.57 \\
0.65 \\
0.58 \\
0.80 \\
0.51 \\
0.54\end{array}$ & $\begin{array}{l}5.27 \\
4.26 \\
3.35 \\
4.78 \\
4.65 \\
5.20 \\
4.76 \\
4.60 \\
5.60 \\
6.12 \\
4.05 \\
6.89 \\
5.48 \\
5.98 \\
4.21 \\
5.95\end{array}$ & $\begin{array}{l}17.1 \\
24.7 \\
20.8 \\
23.5 \\
19.5 \\
16.4 \\
18.2 \\
17.6 \\
14.2 \\
19.6 \\
19.4 \\
15.1 \\
24.0 \\
11.9 \\
25.6 \\
17.4\end{array}$ & $\begin{array}{l}55 \\
96 \\
90 \\
58 \\
48 \\
62 \\
47 \\
75 \\
63 \\
70 \\
98 \\
80 \\
60 \\
73 \\
50 \\
55\end{array}$ & $\begin{array}{r}90 \\
105 \\
70 \\
112 \\
91 \\
85 \\
87 \\
81 \\
80 \\
120 \\
79 \\
104 \\
132 \\
71 \\
108 \\
104\end{array}$ & $\begin{array}{r}5.0 \\
10.0 \\
6.3 \\
6.5 \\
4.4 \\
5.3 \\
4.1 \\
6.1 \\
5.0 \\
8.4 \\
7.7 \\
8.3 \\
7.9 \\
5.2 \\
5.4 \\
5.7\end{array}$ \\
\hline $\begin{array}{l}17 \\
18 \\
19 \\
20\end{array}$ & $\begin{array}{l}\text { ASD } \\
\text { PS } \\
\text { PS } \\
\text { ASD }\end{array}$ & $\begin{array}{l}6 \cdot 80 \\
7 \cdot 77 \\
7 \cdot 27 \\
7 \cdot 28\end{array}$ & $\begin{array}{l}0.78 \\
0.60 \\
0.70 \\
0.65\end{array}$ & $\begin{array}{l}5.30 \\
4.66 \\
5.09 \\
4.73\end{array}$ & $\begin{array}{l}15.7 \\
18.7 \\
18.9 \\
16.0\end{array}$ & $\begin{array}{l}73 \\
67 \\
75 \\
70\end{array}$ & $\begin{array}{l}83 \\
87 \\
96 \\
76\end{array}$ & $\begin{array}{l}6.1 \\
5.8 \\
7.2 \\
5.3\end{array}$ \\
\hline
\end{tabular}

CAD, coronary artery disease; PS, pulmonary stenosis; HCM, hypertrophic cardiomyopathy; VA, left ventricular aneurysm; MR, mitral regurgitation; AV, prosthetic aortic valve; PE, pericardial effusion; ASD, atrial septal defect; MMA, maximal mitral orifice area; MOR, mitral orifice opening ratio; CMA, corrected mitral orifice area; DVI, diastolic maximum velocity integral recorded from position A by pulsed Doppler; HR(D), heart rate during Doppler examination; SV(D) and CO(D), stroke volume and cardiac output by Doppler echocardiography.

corrected mitral area, which can then be regarded as-a constant during diastole.

The Doppler mean velocity is representative of the spatial mean velocity of the whole mitral orifice area only if the blood velocity profile is flat. Experimental data indicate that the velocity profile across the mitral valve is flat except for a zone of high shear near the margin of the anterior leaflet in mid and end diastole. ${ }^{8}$ To our knowledge, there is no such information available in humans. Assuming that there is a flat velocity profile across the mitral orifice during diastole and the angle between the ultrasound beam and the blood flow direction is $0^{\circ}$, the transversed distance of blood can be obtained by integrating the velocity during diastole. Cardiac output (CO) can then be calculated as: $\mathrm{CO}=\mathrm{DVI} \times \mathrm{CMA} \times \mathrm{HR}$, where DVI is the diastolic velocity integral, CMA the corrected mitral orifice area, and HR the heart rate.

\section{ECHOCARDIOGRAPHY}

A phased array cross sectional instrument (IREX III) with a $2.5 \mathrm{MHz}$ transducer was used for both cross sectional imaging and $M$ mode recordings. All patients were examined in the left lateral decubitus position. After the mitral valve orifice had been imaged in the left parasternal short axis view, the transducer was angled to record the maximal mitral orifice area and both leaflet tips. The images were recorded on video tapes. By adjusting the $M$ mode cursor across the middle of the mitral valve orifice, a derived $M$ mode echocardiogram was obtained at a paper speed of $50 \mathrm{~mm} / \mathrm{s}$.

DOPPLER TECHNIQUE

A commercially available multifrequency $(1-10 \mathrm{MHz})$ Doppler instrument (ALFRED, Vingmed), with both pulsed and continuous mode, and a transducer of $2 \mathrm{MHz}$ were used to record the Doppler signals. The instrument has been described in detail elsewhere. ${ }^{6}$ The sample volume in the pulsed mode is approximately $8 \mathrm{~mm}$ in diameter and $5 \mathrm{~mm}$ in length. The received signals were processed by two frequency estimators and converted into analogue voltages in proportion to the mean and maximum Doppler frequency shifts. The electrocardiograms, the mean and maximum velocity curves, the phonocardiograms, and the amplitude of the Doppler signals were recorded simultaneously on a Mingograph 82 electrocardiograph (Siemens Elema) at a paper speed of $50 \mathrm{~mm} / \mathrm{s}$.

The Doppler probe was placed at the apex, and the continuous mode was first used to localise and record the mitral flow signals. The probe was angled by listening to the audio signals to obtain the highest mitral flow velocity. The pulsed mode was then switched on to record the velocities from different positions: (A) where the mitral valve opening was first heard and recorded on the amplitude curves, (B) $1 \mathrm{~cm}$ above $(A)$, and $(C)$ where only the mitral valve closure was heard and recorded. Care was taken to adjust the gain setting properly to minimise noise interference and to avoid the left ventricular outflow area while still maximising mitral flow. 

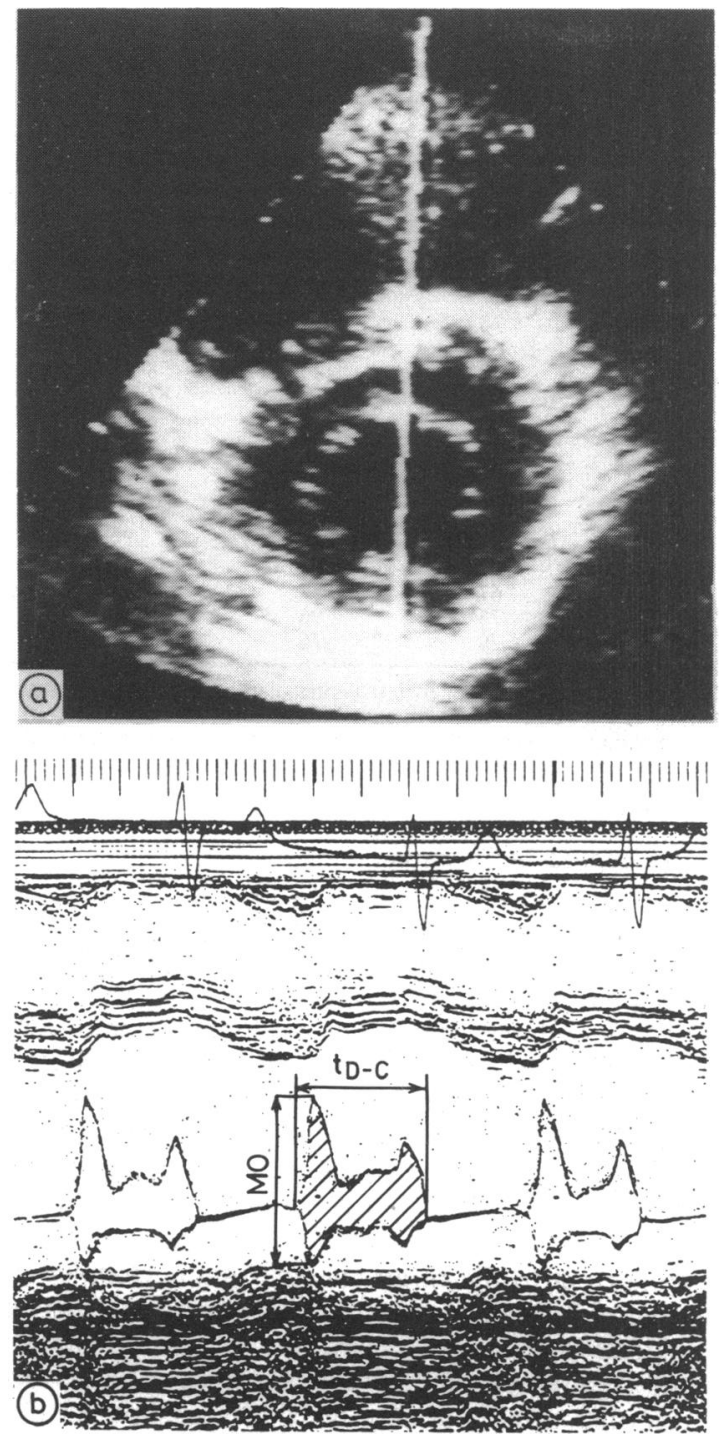

Fig. 1 (a) Short axis echocardiogram showing the maximal mitral valve orifice area and the position of the $M$ mode line. (b) $A$ derived $M$ mode echocardiogram showing the method for calculating the mitral orifice opering ratio. The area between the leaflets was integrated and divided by the time interval between $D$ and $C$ points $\left(t_{D-}\right)$ to obtain the mean opening which, divided by the maximal opening (MO), equals the opening ratio.

\section{DATA ANALYSIS}

The video tape recordings were analysed frame by frame. The frame with the maximal mitral orifice area within one cardiac cycle was selected and digitised by a computer system (CARDIO 80, Kontron) programmed to give a planimetered area. Five to seven consecutive cardiac cycles were analysed and the values averaged (Fig. 1).

The derived $M$ mode echocardiograms were traced manually along the outermost echoes from the mitral valve and digitised by the same computer to determine the following measurements: $(a)$ the opening area enclosed by the two leaflets; $(b)$ the time interval between the $D$ and $C$ points of the mitral valve; $(c)$ the mean opening of the two leaflets, which was obtained by dividing $(a)$ by $(b) ;(d)$ the maximal opening, which corresponds to $\mathrm{EE}^{\prime}$ or $\mathrm{AA}^{\prime}$ depending on which is the larger; and $(e)$ the mean to maximal opening ratio, which was obtained by dividing $(c)$ by (d). Ten consecutive cardiac cycles were digitised and the mean opening ratio calculated (Fig. 1).

The diastolic velocity integral was determined by tracing and digitising the area under the mitral flow velocity curves over 10 cardiac cycles. Since maximum velocities are less affected by errors in aiming than mean velocities ${ }^{69}$ we integrated the maximum velocity curves. The integration was ended at the mitral valve closure component of the first heart sound, which was identified by the recordings at position C. The mitral velocity recorded at position $\mathrm{A}$ was used to calculate cardiac output (Fig. 2).

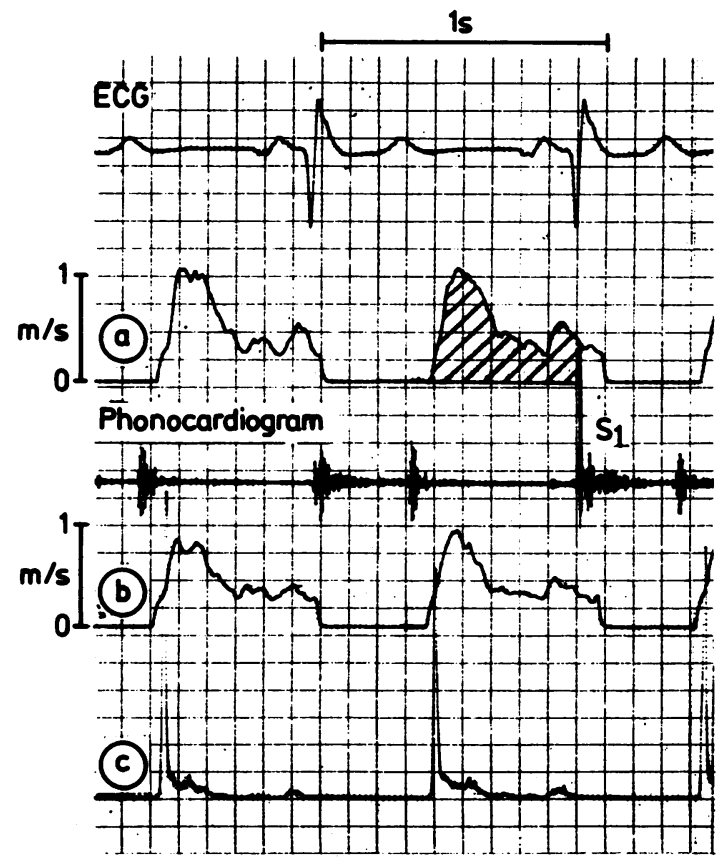

Fig. 2 Electrocardiogram (ECG), phonocardiogram, and pulsed Doppler recordings showing (a) the maximal and (b) mean velocity, (c) the amplitude of Doppler signal, and the technique of integrating the maximum velocity (hatched area). 

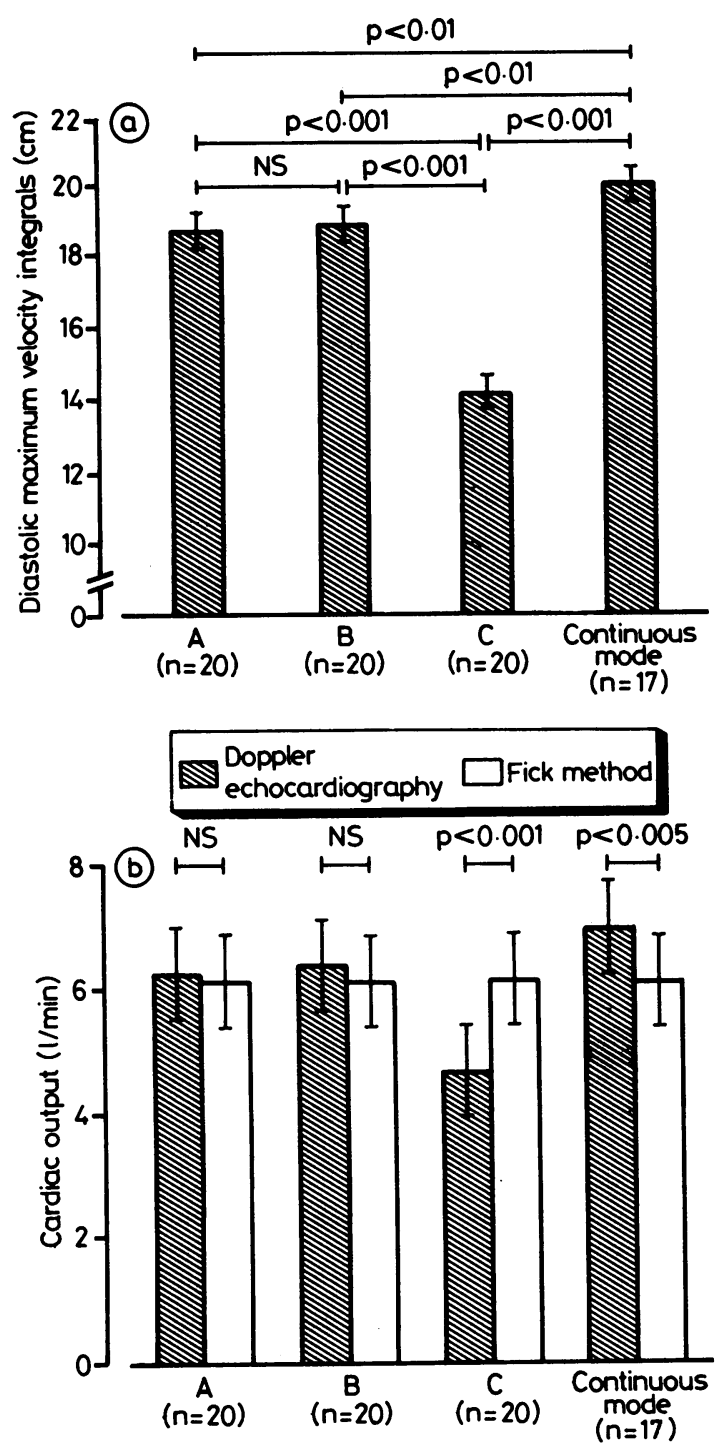

Fig. 3 (a) Diastolic velocity integrals recorded by the pulsed mode Doppler technique from different positions $(A, B$, and $C)$ and by the continuous mode. (b) Cardiac output determined by Doppler echocardiography using different diastolic velocity integrals and by the Fick method. Values are mean (SD).

\section{FICK METHOD}

Cardiac output was measured in the catheterisation laboratory using the standard Fick method. Oxygen in air and blood was measured using ABL-3 and OSM-3 instruments (Radiometer, Copenhagen) respectively. Stroke volume was computed by dividing cardiac output by heart rate measured during the Fick procedure.

\section{STATISTICS}

Statistical analysis was performed using paired $t$ tests and correlation and linear regression analysis. All results are given as mean and 1 standard deviation (SD).

\section{Results}

\section{DOPPLER ECHOCARDIOGRAPHY}

The Table shows the individual results of Doppler echocardiography. Technically adequate recordings of cross sectional and $M$ mode echocardiograms were obtained in all patients. The values for the maximal mitral orifice area varied between 4.65 and $11.02 \mathrm{~cm}^{2}$ $\left(8.21(1.57) \mathrm{cm}^{2}\right)$. The smallest value was found in one patient with coronary artery disease (case 3 ), who also had the lowest stroke volume by Doppler echocardiography. The largest value was found in one (case 16) of the two patients with mitral regurgitation, both of whom were characterised by a high stroke volume by Doppler echocardiography. The values for the mitral orifice opening ratio varied between 0.51 and $0.80(0.62(0.09))$. The highest values were found in two patients with hypertrophic cardiomyopathy (cases 6 and 14), which was related to the reduced EF slope in these patients. The corrected mitral orifice area ranged from 3.35 to $6.89 \mathrm{~cm}^{2}\left(5.05(0.82) \mathrm{cm}^{2}\right)$. The smallest value was found in the patient with the smallest maximal mitral orifice area and the largest value in the patient with a pericardial effusion (case 12).

All Doppler measurements recorded in the pulsed mode were technically adequate, whereas recordings in the continuous mode from three patients were excluded because of noise interference. With the pulsed mode, the diastolic velocity integral from position A ranged from 11.9 to $25.6 \mathrm{~cm}(18.7(3.61) \mathrm{cm})$. There was no significant difference between the velocity integral measured from positions $A$ and $B$, whereas the velocity integral recorded from position $C$ was significantly lower than that from position A $(p<0.001)$ or $B(p<0.001)$. On the other hand, the velocity integral recorded by the continuous mode was significantly larger than that recorded from any of the three positions by the pulsed mode (Fig. 3).

The cardiac output by Doppler echocardiography using the pulsed mode and the diastolic velocity integral from position A ranged from 4.4 to $10.01 / \mathrm{min}$ $(6.3(1.5) \mathrm{l} / \mathrm{min})$. The stroke volume varied between 70 and $132 \mathrm{~cm}^{3}$ (93 (17) $\mathrm{cm}^{3}$ ). The comparison between the maximal mitral orifice area and the stroke volume yielded a significant correlation $(r=0.54$, $\mathrm{p}<0.02$ ), although the values were scattered. There was no significant correlation between the corrected mitral orifice area and the stroke volume $(r=0.33$, $\mathrm{p}>0.05$ ). The correlation between the diastolic velocity integral and the stroke volume was also significant $(\mathrm{r}=0.66, \mathrm{p}<0.005)$. 

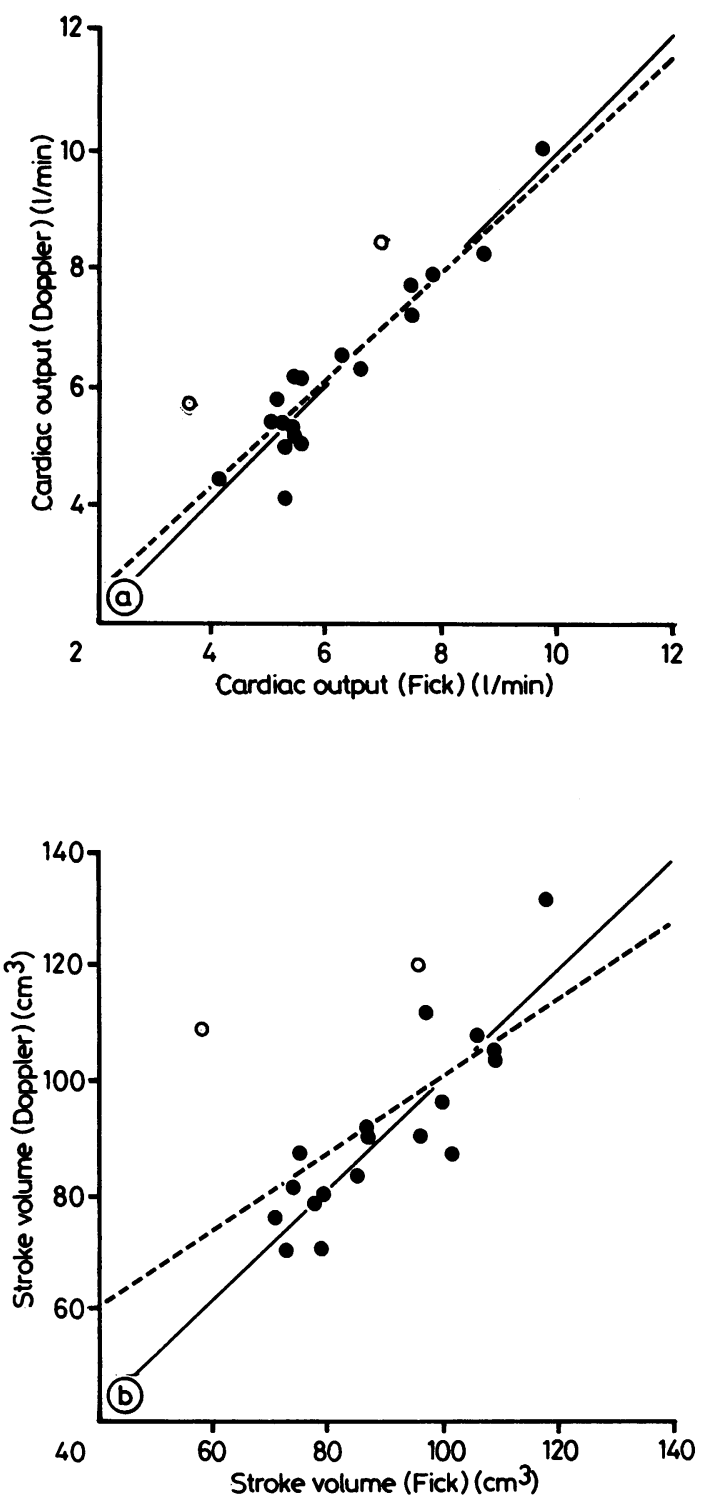

Fig. 4 Comparison of (a) cardiac output and (b) stroke volume determined by Doppler technique and Fick method. (a) In the whole group (broken line) including two patients $(O)$ with mitral regurgitation $(M R)$, the equation for the linear regression was $y=0.90 x+0.80, r=0.89, p<0.001, S E E 0.71$ lmin. In patients without $M R$ (continuous line) the equation was $y=0.97 x+0.22$, $r=0.95, p<0.001, S E E 0.49 \mathrm{l} / \mathrm{min}$. (b) In the whole group (broken line) including two patients $(O)$ with mitral regurgitation $(M R)$, the equation for the linear regression was $y=0.70 x+30.79, r=0.66, p<0.005$. In patients without $M R$ (continuous line) the equation was $y=0.95 x+4.83, r=0.87$, $p<0.001$.

\section{CARDIAC CATHETERISATION}

The cardiac output by the Fick method ranged from 3.8 to $9.81 / \mathrm{min}(6.1(1.5) 1 / \mathrm{min})$. The highest value was found in one normal subject (case 2), who also had the highest cardiac output by Doppler echocardiography. The lowest value was found in one patient with coronary artery disease (case 16), whose cardiac index by the Fick method was $<2.51 / \mathrm{m}^{2}$ per $\mathrm{min}$. The stroke volume varied between 58 and $118 \mathrm{~cm}^{3}(89$ (16) $\mathrm{cm}^{3}$ ). The highest value was in one normal subject (case 13), who also had the highest stroke volume by Doppler echocardiography. The lowest value was in the patient with the lowest cardiac output by the Fick method.

\section{COMPARISON BETWEEN DOPPLER ECHOCARDIOGRAPHY AND CARDIAC \\ CATHETERISATION}

There was a highly significant correlation for cardiac output between Doppler echocardiography and the Fick method $(r=0.89, p<0.001$, Fig 4). In the two patients with mitral regurgitation, however, the Fick results were considerably overestimated by Doppler echocardiography. If these two patients were excluded, an excellent correlation was derived $(r=0.95, p<0.001)$. The cardiac output by the Fick method was not significantly different from that measured by the pulsed mode using the diastolic velocity integral from either position A or B; nevertheless, it was considerably overestimated by the continuous mode and underestimated by the pulsed mode using the velocity integral from position $\mathrm{C}$ (Fig. 3).

There was no significant difference between the heart rates during the Doppler and Fick procedures (68 (15) beats/min vs 69 (13) beats/min), and the stroke volumes derived from the two measurements could therefore be compared. There was a significant correlation of stroke volume between the two techniques $(r=0.66, p<0.005$, Fig. 4). In the two patients with mitral regurgitation, however, stroke volume was also overestimated by Doppler echocardiography. If these two cases were excluded, a highly significant correlation was also obtained $(r=0.87, p<0.001)$.

\section{Discussion}

Volumetric flow measurements using Doppler echocardiography require $(a)$ a correct determination of the cross sectional area, $(b)$ a flat velocity profile at this site, and $(c)$ a near alignment between the Doppler beam and the flow direction. Theoretically, there are two places in the left ventricular inflow tract where the mitral cross sectional area could be measured. One is at the mitral annulus, the inlet of the mitral valve, and the other is at the mitral valve orifice, the outlet of 
the mitral valve. Since the mitral annular cross sectional area is difficult to localise on an echocardiogram the annular diameter has been used to calculate the area. ${ }^{10}$ Ormiston et al showed, however, that changes in a single echocardiographic annular diameter may not predict changes in annular area since both the position and shape of the annulus may change during the cardiac cycle. ${ }^{11}$ On the other hand, the mitral orifice area can be determined precisely by planimetry in the cross sectional short axis view. To achieve an optimal measurement, it is mandatory that the maxmal orifice area at the valve tips should be recorded. In their study, Fisher et al planimetered the mitral orifice area through the middle of the leaflets, ${ }^{7}$ but in most other studies 1213 the mitral orifice area was measured on a trailing to leading edge basis. The latter method has proved to be accurate and reproducible ${ }^{14}$ and hence has been used in the study.

Since the mitral orifice area changes considerably during diastole it is necessary to correct for such variations. Theoretically, it would be more accurate to measure area changes over all diastolic frames. This procedure is, however, tedious and time consuming. Moreover, because the mitral valve tips move in and out of the sectional plane during diastole it is practically impossible to obtain all the cross sectional areas throughout the cardiac cycle. Nevertheless, as the normal mitral orifice is elliptical, ${ }^{8}$ and its area changes are mainly due to the movement of both leaflets in the anteroposterior direction, 1516 such changes could be predicted by the variations in the anteroposterior diameter-that is, the variations of the leaflet separation that can be calculated on derived $M$ mode echocardiograms. The mean to maximal opening ratio, as described previously by other workers, ${ }^{6} 17$ is a correction factor for the changes in diastolic area. In contrast to their method of dividing the $M$ mode diastolic recording into $0.05 \mathrm{~s}$ segments in one cardiac cycle we performed planimetry of the whole separation area over 10 cardiac cycles, which may provide a more accurate mean opening diameter and opening ratio.

The diastolic flow pattern through the mitral valve in sinus rhythm is complex including two acceleration and deceleration phases combined with alterations in cross sectional area. Despite this, experiments on normal mitral valves have shown a fairly flat velocity profile at the mitral annulus and a slightly peaked profile at the valve orifice. ${ }^{8}$ The Doppler measurements therefore estimate the mean spatial velocity profile with a reasonable degree of accuracy provided that it is made at the site where the area is determined and in alignment with the flow direction. Duplex Doppler echocardiography has reduced these problems by visualising the sample volume and showing the Doppler angle within the sectional plane.
Nevertheless, the angle within the elevational or azimuthal plane still cannot be determined. ${ }^{17}$ In such circumstances, we believe that the single Doppler technique using the apical approach and the audio signals is well able to obtain an optimal beam direction for the mitral flow. By moving the Doppler sample from the left ventricle step by step to the left atrium, the amplitude signal from the mitral valve movement can be recorded and used to determine the optimal sample location. The level at which the valve opening is first recorded (position A) is probably the level of the mitral valve tips. This statement may not be true because the mitral valve moves constantly relative to the chest during diastole. We therefore measured the velocity at position $B(1 \mathrm{~cm}$ above position A). The fact that there was no significant difference in the velocity integral between the two positions indicates that small changes in sample location are unimportant in the measurement of mitral flow. On the other hand, the velocity integral recorded from position $\mathrm{C}$ was signficantly smaller than that from either A or B. The reason for this is probably that at this level the sample has reached the mitral annulus whose area is much larger than that of the mitral orifice so that the flow velocity is decreased. These findings agree with previous observations. ${ }^{18}$

The good correlations of cardiac output and stroke volume between pulsed Doppler echocardiography and the Fick method obtained in this study confirm the reliability of the mitral orifice method in determining cardiac output. Although we did not measure cardiac output simultaneously by the two techniques, similar heart rate during the two examinations suggests that there was no important haemodynamic difference between the two procedures. In contrast, cardiac output was significantly overestimated by the continuous mode. This is probably because when a sample volume in the mitral flow canal approaches the left atrium the early diastolic velocity decreases, whereas the late diastolic velocity increases. ${ }^{18}$ The continuous mode picks up both the highest early and late diastolic velocities, resulting in an overestimated cardiac output. It seems, therefore, that in the mitral orifice method only the pulsed mode can be used. Our data also show that both the diastolic velocity integral and the maximal mitral orifice area correlated significantly with the stroke volume by Doppler echocardiography; nevertheless, because the values are scattered use of either the mitral echocardiograms $^{19}$ or mitral flow characteristics alone is an unreliable method for estimating cardiac output.

There are some limitations to this method. Firstly, mitral valve disease makes the measurement unreliable, as shown by the two patients with mitral regurgitation. Secondly, any congenital heart disease with a shunt below the level of the mitral orifice would pro- 
duce similar results. Finally, since both area and flow of the mitral orifice are very variable measurement of a number of cardiac cycles is necessary and hence time consuming.

$\mathrm{YZ}$ is a research fellow from the Cardiovascular Institute, Shandong Medical College, People's Republic of China.

\section{References}

1 Magnin PA, Stewart JA, Myers S, Ramm OV, Kisslo JA. Combined Doppler and phased array echocardiographic estimation of cardiac output. Circulation 1981; 63: 388-92.

2 Schuster AH, Nanda NC. Doppler echocardiographic measurement of cardiac output. Comparison with a non-golden standard. Am $\mathcal{F}$ Cardiol 1984; 53: 257-9.

3 Goldberg SJ, Sahn DJ, Allen HD, Valdes-Cruz LM, Hoenecke $\mathrm{H}$, Carnahan Y. Evaluation of pulmonary and systemic blood flow by 2-dimensional Doppler echocardiography using fast Fourier transform spectral analysis. Am f Cardiol 1982; 50: 1394-400.

4 Huntsman LL, Stewart DK, Barnes SR, Franklin SB, Colocousis JS, Hessel EA. Noninvasive Doppler determination of cardiac output in man. Clinical validation. Circulation 1983; 67: 593-602.

5 Loeppky JA, Hoekenga DE, Greene ER, Luft UC. Comparison of non-invasive pulsed Doppler and Fick measurements of stroke volume in cardiac patients. Am Heart f 1984; 107: 339-46.

6 Ihlen HI, Amlie JP, Dale J, et al. Determination of cardiac output by Doppler echocardiography. Br Heart $\mathcal{F}$ 1984; 51: 54-60.

7 Fisher DC, Sahn DJ, Friedman MJ, et al. The mitral valve orifice method for noninvasive two-dimensional echo Doppler determinations of cardiac output. Circulation 1983; 67: 872-7.

8 Taylor DEM, Whamond JS. Velocity profile and impedence of the healthy mitral valve. In: Kalmanson D, ed. The mitral valve. A pluridisciplinary approach. London: Edward Arnold, 1976: 127-36.
9 Brubakk AO, Givold SE. Pulsed Doppler ultrasound for measuring blood flow in the human aorta. In: Hatle L, Angelsen B, eds. Doppler ultrasound in cardiology. Philadelphia: Lea and Febiger, 1982: 185-93.

10 Valdes-Cruz LM, Horowitz S, Sahn DJ, et al. A simplified mitral valve method for 2D echo Doppler cardiac output [Abstract]. Circulation 1983; 68 (suppl III): III230.

11 Ormiston JA, Shah PM, Tei C, Wong M. Size and motion of the mitral valve annulus in man. I. A twodimensional echocardiographic method and findings in normal subjects. Circulation 1981; 64: 113-20.

12 Nichol PM, Gilbert BW, Kisslo JA. Two-dimensional echocardiographic assessment of mitral stenosis. Circulation 1977; 55: 120-8.

13 Martin RP, Rakowski H, Kleiman JH, Beaver W, London E, Popp RL. Reliability and reproducibility of twodimensional echocardiographic measurement of the stenotic mitral valve orifice area. Am f Cardiol 1979; 43: $560-8$.

14 Marino P, Zanolla L, Nidasio GP, Nicolosi GL, Fabbri A. Interpretative reproducibility of two-dimensional echocardiographic images. Analysis of intraobserver, interobserver and beat to beat reproducibility of the mitral valve orifice. Eur Heart f 1983; 4: 733-7.

15 Taylor DEM, Wade JD. Pattern of blood flow within the heart: a stable system. Cardiovasc Res 1973; 7: 14-21.

16 Roelandt J, ten Cate FJ, van Dorp WG, Ligtvoet CM, Lancee CT. Ultrasonic two-dimensional analysis of the mitral valve. In: Kalmanson D, ed. The mitral valve. A pluridisciplinary approach. London: Edward Arnold, 1976: 333-46.

17 Valdes-Cruz LM, Horowitz S, Messl E, et al. A pulsed Doppler echocardiographic method for calculation of pulmonary and systemic flow: accuracy in a canine model with ventricular septal defect. Circulation 1983; 68: 597-602.

18 Hatle L, Angelsen B, eds. Doppler ultrasound in cardiology. Philadelphia: Lea \& Febiger, 1982: 60-2.

19 Rasmussen S, Corya BC, Feigenbaum H, et al. Stroke volume calculated from the mitral valve: echograms in patients with and without ventricular dyssynergy. Circulation 1978; 58: 125-33. 